\title{
ECOTURISMO EN MADRE DE DIOS (PERÚ). UNA PROPUESTA DE INVESTIGACIÓN
}

\author{
M. Patricia Cadenas Erazo*
}

La teoría de la construcción social de la naturaleza propuesta por Klaus Eder $^{1}$ permite realizar investigaciones sociales, desde una perspectiva histórica y comparativa, que conlleven a la identificación de los sistemas simbólicos de las sociedades que practican el ecoturismo.

Para el caso de la Amazonía peruana, el ecoturismo que practican algunas comunidades de Madre de Dios resulta particularmente interesante como estudio de casos que pueden ser abordados desde esa perspectiva, contribuyendo con ello a establecer una definición del ecoturismo específico de dicha zona, vinculada directamente a la realidad del departamento de Madre de Dios, por medio de las experiencias ecoturísticas de Posada Amazonas y Casa Matsiguenka.

\section{DESCRIPCIÓN DEL PROYECTO}

Se busca caracterizar las actividades ecoturísticas en el Perú, mediante el estudio comparativo y balance de dos experiencias ecoturísticas en las comunidades nativas amazónicas de Infierno en Tambopata y de Tayakome y Yomibato en el Manu, involucradas actualmente en la práctica del ecoturismo. De esta manera podrá establecerse en qué medida y forma el discurso ecoturístico es adoptado por las comunidades protagonistas y si realmente ejerce las funciones de desarrollo y sostenibilidad que le son adjudicadas.

Infierno es una comunidad mixta con componentes nativos ese'eja (familia lingüística tacana) y colonos (ribereños o inmigrantes) que, en alianza con la empresa privada Rainforest Expeditions ${ }^{2}$, ha creado el albergue Posada Amazonas al sureste de la selva peruana, en las proximidades de la Reserva Nacional de Tambopata. La participación de los pobladores en el proyecto ecoturístico es laboral y son beneficiarios del $60 \%$ de las utilidades. De igual manera, existe capacitación y talleres que coadyuvan a la formación y perfeccionamiento de la comunidad hasta el momento en que puedan tomar las riendas en la administración y organización de la empresa.

En líneas generales, puede decirse que el proyecto Posada Amazonas cumple aparentemente con las recomendaciones para la conservación local y de desarrollo sostenible, siendo su atracción principal la observación de aves. Se cuenta también con un centro de investigación en la zona.

- Maestria de Gestión Cultural, Patrimonio y Turismo, Facultad de Ciencias de la Comunicación, Turismo y Psicologia, Universidad de San Martin de Porres, Lima.

1 Klaus Eder. The Social Construction of Nature. A Sociology of I cological Enhghtenment. London-Thousand Oaks-New Delhi, SAGE, 1996.

2 En 1996, la comunidad nativa de Infiemo firmó un contrato con la empresa Rasinforest Expeditions para la creación de un establecimiento ecoturistico. Los téminos del contrato fueron replanteatlos en 1999. 
El proyecto Casa Matsiguenka ${ }^{3}$, albergue tradicional que funciona desde 1998 por iniciativa $y$ cuenta propia de esta misma comunidad, en las proximidades del río Manu y en el Parque $\mathrm{Na-}$ cional del mismo nombre, ha recibido el asesoramiento de $\mathrm{FANPE}^{4} / \mathrm{CTZ}^{5}$ para la organización y desarrollo de sus prácticas ecoturísticas. Entre los objetivos más importantes de este proyecto se puede mencionar el conocimiento del bosque tropical y de las etnias que habitan esta zona en el Manu.

Conociendo las distintas teorías que explican la forma de relación del hombre con la naturaleza $y$, desde la perspectiva del desarrollo sostenible, las discusiones sobre tradición y modernidad serán retomadas para ver el conflicto conservación-uso a través de la interacción establecida entre la naturaleza y dichas comunidades, que atañe directamente al impacto del ecoturismo en ambas comunidades. Así, el análisis sobre las prácticas ecoturísticas en Posada Amazonas y Casa Matsiguenka tendrá la finalidad de establecer las particularidades y mecanismos con que cada caso se ejecuta, toda vez que constituyen ejemplos únicos de comunidades nativas participando directamente en la concepción, organización y ejecución del ecoturismo en la región. El conocimiento de dichas realidades permitirá la realización de un balance sobre el desarrollo ecoturístico en la Amazonía peruana, establecer sus estándares ecoturísticos y la viabilidad de un modelo de desarrollo turístico alternativo, cuyo concepto sea replicable para el Perú.

\section{Objetivos}

General

Comprender la forma en que el discurso del desarrollo sostenible, según los estándares mundiales establecidos, es adoptado y practicado por las comunidades de Infierno y Tayakome y Yomibato en el desenvolvimiento de sus actividades ecoturísticas en Posada Amazonas y Casa Matsiguenka, respectivamente.

\section{Específicos}

1. Establecer el grado de involucramiento de las comunidades receptoras, Infierno en Tambopata y Matsiguenka del Manu, en las prácticas ecoturísticas.

2. Definir el rol local comunitario de Infierno y matsiguenka en la actividad ecoturística.

3. Conocer las prácticas tradicionales de las comunidades locales, esenciales y favorecedoras para el desarrollo del ecoturismo en sus respectivas localidades.

4. Establecer el grado y tipo de participación femenina en las prácticas ecoturísticas.

5. Establecer el beneficio de las comunidades receptoras y el grado de conservación ambiental como resultado de las prácticas ecoturísticas en sus respectivas localidades.

6. Constatar el grado de satisfacción de los ecoturistas en Posada Amazonas y Casa Matsiguenka respectivamente.

7. Configurar un cuerpo de prácticas turísticas consideradas sostenibles para el Perú.

8. Establecer la forma o apariencia que adoptan las prácticas ecoturísticas en el Perú.

9. Determinar los elementos que garantizan la práctica del ecoturismo en el Perú.

10. Dar una definición de ecoturismo para la realidad peruana.

\section{STATUS QUAESTIONIS}

Acompañando el estudio comparativo, se plantea un balance de la literatura vinculada con los conceptos de desarrollo y sostenibilidad. Su revisión

3 En mayo de 1997, los malsiguenka empezaron la construcción de un albergue, ubicado en la quebrada Salvadorcilio. El 28 de junio de 1997 la empresa se constituyó legalmente.

4 Fortalecimiento del Sistema Nacional de Áreas Protegidas por el Estado.

5 Cooperación Técnica Alemana. 
resulta útil para contextualizar el surgimiento de este último concepto $y$, a partir del mismo, del ecoturismo que comprende la idea de desenvolvimientos $y$ acciones locales a través del manejo patrimonial (natural y cultural) como base de una política de desarrollo.

Las nociones antropológicas de tradición, cambio y progreso relacionadas a la concepción de desarrollo están preñadas de no pocas consecuencias. Han sido abordadas desde distintas perspectivas y desde hace ya buen tiempo, sin dar a ciencia cierta una propuesta de solución integradora o, por lo menos, conciliadora. A menudo se suele oponer lo tradicional como sinónimo de obsoleto y poco confiable frente a lo moderno como símbolo de apertura hacia formas de vida más civilizadas y dignas.

Para formarse un concepto integral de desarrolio, resulta útil la revisión de distintos autores que trabajaron la noción de evolución en el siglo $\mathrm{XIX}$ y principios del $\mathrm{XX}$, tanto desde la perspectiva de las ciencias naturales como de las ciencias sociales. El científico escocés Lyell ${ }^{6}$, con su idea del uniformitarismo, planteó la invariabilidad de los procesos geológicos terrestres como una suerte de patrones de cambio a través de los cuales se podría obsenar el estado actual de la Tierra, lo que resumió en la siguiente frase: "el pasado es la llave del presente".

Comte ${ }^{7}$, hablando sobre el conocimiento experimental, y Darwin ${ }^{8}$, con su concepto de evolución del mundo orgánico, marcaron la trascendencia del principio de evolución a la mayoría de las disciplinas científicas, pero fue $\operatorname{Marx}^{9}$ quien lo acopló al estudio de la política, economía y sociedad, mediante el argumento de que son las fuerzas y los conflictos naturales derivados del capitalismo los que dan paso a la evolución social.
Desde Marx, podrían incluirse en un acápite las consideraciones sobre la integración al mercado como el proceso que inicia la ruptura de una tradición y conduce la transición hacia una nueva clase de sociedad ${ }^{10}$ : Emile Durkheim ${ }^{11}$ atribuyó la evolución social al mercado de capitales, caracterizando como sociedades simples aquellas formas de vida no especializadas y mecánicas, donde la gente actúa y piensa similarmente ejecutando las mismas tareas y teniendo las mismas metas de grupo; por lo tanto, las sociedades complejas se diferenciarían por constituir formas de vida donde la gente no está unida unos a otros, la especialización y jerarquización organizan el trabajo y los vínculos sociales son impersonales.

Siguiendo con la misma tónica de caracterización social, Ferdinand Tonnies ${ }^{12}$ distinguió entre Gemeinschaft y Gesellschaft para hablar de la comunidad en la cual los individuos interactúan en base a principios de reciprocidad colectiva, $y$ de la ciudad donde el principio de competición y las motivaciones personales y egocéntricas constituyen los ejes de las relaciones sociales.

Al describir los cambios que se van presentando conforme un determinado tipo de sociedad se encamina hacia el sistema capitalista, Weber ${ }^{13}$ explicó el proceso de racionalización y burocratización de las sociedades. Por su parte, Robert Redfield ${ }^{14}$ estudió las relaciones entre sociedades urbanas y rurales del Yucatán. Su teoría del folk-urban continuum señalaba una escala de las sociedades en tanto se producía la evolución progresiva de estas en el tiempo hacia formas más civilizadas y complejas, desde los polos rurales o folk hasta los polos urbanos caracterizados por su gran heterogeneidad, desorganización, individualismo y secularización.

6 Charles Lyell. Principios de geologia, 3 vols., John Murray, London, $1830-33$ cit. en Amanda Stronza, Porque es de nosotros. El ecolurismo comunitario en la Amazonia peruana. Tesis doctoral, ms., Universidad de Florida, 2000: 15

7 Auguste Comie. The Positive Philosophy. New York, D. Appletor \& Company, 1854, cit. en Amanda Stronza, op. cit.: $15,170$.

8 Charles Darwin. Origin of Species. New York, New American Library, Mentor, 1958 [1859], cit. por ibidem.

9 Charles Marx and Frederick Engels. The Communist Manifesto. New York, Labor News Co., 1948 [1887], cit, en Amanda Stronza, op. cit.: $15,177$.

$10 \mathrm{~L}$ integración al mercado vista más como un mecanismo conducente al cambio rápido de los valores de la identidad cultural en las relaciones sociales que co mo una forma de obtener más altos ingresos.

11 Emile Durkheim. Division of Labor in Society. New York, MacMillan, Simpson, G., trans., 1933 [1893), cit. en Amanda Stronza, op. eit.: 15, 171.

12 Ferdinand Tonnies. Communify and Society. New York, Harper, 1963, ci1. en Stronza, op. cit.: 1S, 185.

13 Max Weber. La ética protestanie y el espiritu del capitalismo, $17^{2}$ ed. Barcelona, Peninsula, 1999.

14 Robert Redfield, The Folk Culture of the Yucatán. Chicago, University of Chicago, 1941, cit. en Stronza, op. cit:: 15-16, 181. 
Después de la Segunda Guerra Mundial, Dal$\operatorname{ton}^{15}$ y Foster ${ }^{16}$, en el marco de las teorías modernizadoras sobre progreso y desarrollo, junto a otros estudiosos sociales, creyeron encontrar las causas del atraso y la pobreza en ciertos elementos persistentes al interior de las sociedades, que se arrastraban con los valores inculcados por la tradición, la religión, la etnia, la monarquía, así como con otras tantas costumbres del pasado.

Como consecuencia, la solución propuesta desde la perspectiva modernizadora fue la transferencia de tecnología occidental a gran escala hacia lo que ellos identificaban como Tercer Mundo con el fin de incrementar los ingresos per cápita y satisfacer las necesidades básicas, incluyendo educación y salud.

La ecuación del desarrollo definía entonces un paso fuera de lo tradicional como un paso hacia el progreso, vale decir "importación del desarrollo" para traer las últimas ideas y tecnologías que en esencia servirían para inculcar hábitos y valores modernos entre la gente y las sociedades tradicionales. Al respecto, Rostow ${ }^{17}$ describió los estados de desarrollo por los cuales todas las sociedades necesitaron pasar antes de despegar a la modernización, y Escobar ${ }^{18}$ delineó una trayectoria unilineal evolutiva distinguiendo entre sociedades subdesarrolladas, en desarrollo y desarrolladas.

Como antítesis de la tesis modernizadora, surgió la teoría de la dependencia. Los teóricos de la CEPAL y sus continuadores -Cardoso y Faletto ${ }^{19}$, Gunder Frank ${ }^{20}$ entre otros-, si bien no dejaron de reconocer el crecimiento de los países latinoamericanos guiados por los programas modernizadores, observaron, hacia la década de 1970 , que gran parte de la riqueza generada por estos programas beneficiaban más a los sectores sociales y económicos de élite que a la gran mayoría poblacional, pobre y marginada.
Debido a que los indicadores económicos reflejaban la desventaja de los más pobres, quienes en realidad nunca estuvieron en mejor posición, las fallas de la modernización se hicieron más evidentes al bordear los 80 . Mientras tanto, un problema relativamente diferente sentó precedentes, especialmente la alteración del hábitat natural por la pérdida de especies, y otro, consecuentemente, hacía su aparición: el desarrollo había alterado asimismo las culturas locales siguiendo los criterios de transferencia de tecnología y elevación del ingreso per cápita, creando ataduras en la comunidad, antes de haber incorporado con éxito las condiciones de calidad de vida requeridas.

Esta preocupación frente a los impactos generados por la integración de las sociedades rurales al mercado trajo consigo también la preocupación de cómo estos impactos estaban afectando el tratamiento del medio ambiente. Las políticas de desarrollo y planificación en los países tropicales fueron sometidas a reconsideraciones, y con ello la mentada modernización, señalándose que el turismo convencional en lugar de aliviar la pobreza había introducido nuevos problemas sociales (mercado negro, drogas y prostitución) y que su naturaleza suntuaria estaba asociada a gastos lujosos y traslados masivos que provocaban la degradación del medio ambiente.

En 1983, la Comisión Mundial sobre Medio Ambiente y Desarrollo (CMMAD) recibió el encargo de preparar un Programa Mundial para el Cambio, presentado y publicado en un informe de $1987^{21}$, bajo el título de Nuestro futuro común (Informe Bruntland), a partir del cual todos los esfuerzos para hacer viable el progreso económico y social debían dejar de lado cualquier forma de explotación indiscriminada de los recursos naturales, a la vez que se recomendaba fortalecer y ampliar la aplicación de leyes y

15 G Dalton, ed. Inbal and Peasart Lconomies: Readings in fconomic Anthropology. New York. The National History Press, 1967 , cil. en 5 tronza, op. cit: $16,170$.

16 George foster. Iradtional Socreties and Technological Change. New York. Harper and Row Publishers, 1973, cit. en \$tronza, op. cit.: 16, 171.

17 Walter Rostow. The Stages of fconomic Growth: A Non-Communist Aanifesto. Cambritge, Cambridge University Press, 1960 cit. en Sttonza, op. cit.: 16 , 169.

18 Arturo Escolsar "Anthropology and the Development Encounter: The Making and Marheting of Development Anthropology". En American Ethnologist, $n^{\circ} 18,199$ 658.682 , cit en Stronza, op cit: 16, 171; Arturo Escobar y Sonia Alvafez. The Mlaking of Social Movements in Latin America. Westview Press, Boulder, 1992, cit. en ibidem

19 Fernando $\mathrm{H}$, Cardoso y Enzo Faletto. Dependencia y desarrollo en América Latina México, Siglo XXI, 1969

20 André Gunder-frank. América Latma: subdesafrollo o revolución. México, Era, 1963.

21 El concepto de desarrollo sostenible es inhroducido oficialmente por el informe de la Comisión Mundial de Medio Ambiente y Desarrollo, Nuestro futuro común. Oxford, Oxford University Presss, 1987, cit, En Whelan et at, op, cir: 29. 
acuerdos internacionales en favor de un desarrollo sustentable, reafirmando además el derecho soberano de las naciones a explorar $y$ explotar sus recursos.

Desde distintas orientaciones, biólogos, economistas y antropólogos empezaron a confluir sus perspectivas para dar solución a los problemas de desarrollo y conservación; lo mismo se hizo a nivel gubernamental. La premisa desde la cual se partía era compatibilizar los fines de conservación con bienestar económico y hacer esto extensible hacia las generaciones venideras; es decir, encontrar valor económico a los recursos naturales y asegurar beneficios económicos a los administradores locales que, a final de cuentas, son quienes protegen directamente dichos recursos.

Con tal diagnóstico, alternativas inéditas de desarrollo empezaron a registrarse. Nuevas ideas fueron aplicadas en numerosos estudios que aparecieron entre fines de 1980 y principios de $1990^{22}$, utilizando medios de valor económico que ayudaran a mantener intacta la biodiversidad en las regiones de selva tropical.

Algunos investigadores sugirieron que el mercado podía mejorar las condiciones de vida de la gente, toda vez que la integración de las comunidades rurales a este podía facilitar el acceso a mayores ingresos, mejor educación y calidad sanitaria, haciendo posible la disminución de la carga poblacional y generándose mejores oportunidades de conservación. También empieza a hablarse de nuevas formas de turismo más limpias $y$ verdes ${ }^{23}$. En cambio otros argumentaron que la integración al mercado traería nuevos problemas, incluyendo la exposición a enfermedades foráneas y sociales, cambios de formas de vida, incremento de conflictos sociales y decrecimiento general en el bienestar de la gente, que darían como resultado la degradación social y ambiental.

McNeely ${ }^{24}$ ha hablado de alicientes económicos que conducirían a dejar la sobreexplotación de los recursos por otras formas más sostenibles de uso, generando así una nueva conciencia económica en estrecha armonía con la conservación. John Robinson y Kent Redford ${ }^{25}$ señalaron la necesidad de añadir valor económico a la vida silvestre, a fin de que esta adquiriese algún valor de uso para la gente y pudiese ser objeto de conservación.

Poco después, en uno de los artículos compilados por el mismo Redford ${ }^{26}$, una experiencia concreta ${ }^{27}$ retomó dichos argumentos en relación al valor económico y conservación de los recursos para la región guatemalteca del Petén. Los resultados revelaron que las familias dedicadas a la cosecha de goma, chicle y especias se constituían como fuertes promotoras de la protección forestal en razón del conocimiento que tenían acerca del uso sostenible de estos recursos como garantía de su futuro económico.

Similares modelos se aplicaron al análisis del turismo. Mendelsohn y Tobias ${ }^{28}$, para Costa Rica, intentaron calcular el porcentaje de territorio protegido a través de la actividad turística en una determinada zona de la selva, expresándolo en

22 Ricardo Godoy, Ruben Lubowski and Aul Markandya. "A Method for the Economic Valuation of Non-Timber Forest Products". En Economic Botany 47, 1993: 220-233, cit en Stronza, op et : 19,173: Gutsertez, B and D. W Pearce. "Estimating the Environmental Benefits of the Amazon Forest: An International Valuation Exercise En Centre for Social and Lconomic Research on the Fovironment Policy Paper. London, University College London Press, 1992, cit. en Stronza, op. ctt: 19, 174, D. W. Pearce. The Economic Value of Biological and Cultural Diversity. Report to the World Conservation Union. London, University CollegeCentre for Sucial and Economic Resparch ors the Global Environment, 1992, cit, en Stronza, op. cit: 19, 180; Peters, C. M., Alwyn Gentry, and Mendelsolon. “Va. luation of an Amazonian Rainforest". En Nature 339, 1989: 655-656, cit. en ibidem.

23 Marlha S. Honey. "Treading liglydy? ecotoufism's impact on the chvironmenl" En Envinonment 41, 1994: 4, cit. en Stronza, op. cit.: 17. 175.; 1. Munt. "Eco-Tourism or Ego-Touriom?" En Race and Cliss 36, 1994: 49-60, cit. en Stronza, op cit: 17, 178.

24 Jeffrey Me Neely. Fconomics and Biologrcal Diversty. Ciland, Swilzerland, International Union for flue Conservation of Nature and Natural Resources, 1988, cit. en Stronza, of cit: 18,177

25 folm G. Rolyinson and Kent H. Redlord, eds. Neolropical Wildive Use and Canservalion. Chicugo, Lniversity of Chicago Press, 1991, cit. en Stronza, op. cit: 19, 181.

26. Kent H. Redforl and Christinn Padse h, eds. Consenvalion of Neotropical Forests: Working Irom Traditional Resource Use. New Vork, Columbia Universily Press, 1992 , cit. en ibidem.

27 lames Nations. "Xateros, Chicleros, and Pimenteros: Hamestion Renewabla Tropical Forest Resources in the Guatemalan Peten". En H. Redford and C. Padoch, eds., op cit: $208-219$, cil en Stron $2 \mathrm{a}$, op cit: $19,178-179$.

28 R. O Mendelsohn and D. Tobias. "Valuing Ecolourism in a Tropical Rainforest Reserve". En Ambio 20, 1991: 91.93 , cit. en Stronza, op cit: 19, 177. Ver también Susan Menkhaus antl Douglas Lober. "Intemational Ecotourism and the Valuation of Tropical Rainforesis in Costa Rica". En loumal of Environmental Marnagement 47, $1996: 1-10$, cit en Sironza, op $\mathrm{ctt}: 17,171-172$ 
cantidades monetarias y comparándolo, a su vez, con el precio más bajo del terreno en el mercado para demostrar que el turismo era una mejor opción para la gente.

De igual manera procedió Webster ${ }^{29}$ en el Parque Nacional de Amboseli (Kenya, África) donde se registraban los más altos ingresos de divisas por concepto de turismo, cuyos principales atractivos llegaron a estimarse en $\$ 27,000$ por cada león y $\$ 610,000$ por cada elefante al año. Ante el agravamiento de la contaminación ambiental y por recomendación del Informe Bruntland, se determinó la convocatoria para la Conferencia de las Naciones Unidas sobre el Medio Ambiente y el Desarrollo (UNCED / CNUMAD), conocida como ECO-92 o Cumbre de la Tierra, llevada en a cabo en junio de 1992 en Río de Janeiro, Brasil. Bajo el lema "Hay que salvar a la Tierra" se alcanzó una serie de acuerdos plasmados luego en documentos que no tienen fuerza jurídica pero que significan la instauración de una conciencia ecológica en el orden mundial, a saber ${ }^{30}$ :

- Convenio sobre cambio climático, con el que se acordó la disminución de la emisión del dióxido de carbono por ser el causante del progresivo calentamiento del planeta ("efecto invernadero") y peligrosas alteraciones en la naturaleza.

- Convenio sobre biodiversidad para la conservación de la diversidad biológica ${ }^{31}$, la utilización sostenible de sus componentes y la participación justa y equitativa en los beneficios derivados de la utilización de los recursos, regulando al mismo tiempo la explotación tecnológica de la riqueza genética de las especies de plantas y animales por parte de los países desarrollados en los países tercermundistas o en desarrollo. EE.UU. no firmó este documento por considerarlo lesivo a su política de equilibrio entre ecología y economía. Fue ratificado por el Perú el 7 de junio de 1993. Asimismo, mediante D.S. 102-2001-PCM, se aprobó la Estrategia Nacional de Diversidad Biológica.
- Declaración de Principios de Florestas, con el fin de lograr el consenso mundial respecto de la ordenación, conservación y desarrollo sostenible de los recursos forestales, tomando en cuenta:

- la política forestal de los países para reconocer y apoyar debidamente la cultura y respetar los derechos y los intereses de las poblaciones indígenas, de sus comunidades y de los habitantes de las zonas boscosas;

- la función vital que cumplen los bosques en el mantenimiento y equilibrio de los procesos ecológicos y como sumideros de carbono;

- el acceso a tecnologías en términos favorables, preferenciales y concesionales de los países que desarrollen una gestión nacional de sus recursos forestales.

- Agenda 21 que propone las áreas de acción para lograr el desarrollo sostenible en el siglo $X X I$. Entre esas acciones se encuentran:

- la protección de la atmósfera y el apoyo al estudio y la investigación sobre las cuestiones del ambiente y del desarrollo que guardan relación con el aire que nos rodea;

- medidas contra la deforestación, la desertificación y la sequía y la gestión de los ecosistemas frágiles como montañas, sierras semiáridas, marismas, pequeñas islas y ciertas zonas costeras;

- gestión racional y con parámetros ecológicos de los residuos urbanos, sólidos y líquidos, químicos tóxicos, peligrosos y radiactivos.

- protección de los océanos, de los mares, las aguas dulces y las zonas costeras, con una utilización racional de sus recursos vivos $y$ de su hábitat.

- mecanismos financieros para desarrollar las acciones previstas y el fortalecimiento de las instituciones actuales para lograr un desarrollo económico acorde con la conservación de la naturaleza.

29 Cit. en McNeely, op cit: 20, cit. en Stronza, op. cit: 18, 177.

30 Ver www oni.escuelas edu ar/olimpi99/libros-digitales/htm/ecologia.htm

31 La definición que el propio convenio da del concepto de diversidad biológica es: la "variabilidad de organismos vivos de cualquier frente, incluidos entre otras cosas, los ecosistemas terrestres y marinos y otros sistemas acuáticos y los complejos ecologicos de los que forman parte, comprende la diversidad dentro de cada especie, entre las especies y de los ecosistemas". En un sentido amplio, la biodiversidad es la variedad y variabilidad de los seres vivos en los sistemas ecologicos que los albergan. Es decir, el termino incluye varios niveles fundamentales: paisajes, ecosistemas, comunidades, especies, poblaciones y genes. 
La Agenda 21 para la Industria de Viajes y Turismo, aprobada en 1995 por la Organización Mundial del Turismo (OMT), junto con el Consejo Mundial de Viajes y Turismo y el Consejo de la Tierra, viene a ser un programa en el que dicha industria formula su papel específico en el logro de los objetivos de la Agenda 21 concernientes a: planificación del desarrollo sostenible del turismo, la participación de todos los sectores sociales en el turismo o el diseño de nuevos productos turisticos centrados en la sostenibilidad, y diez tipos de actuación prioritarios (minimización de los residuos, la conservación de energía, el control de los recursos de agua potable, el control de las aguas residuales, entre otros).

- Declaración de Río, documento que recoge los principios básicos para una nueva y equitativa alianza mundial, reafirmando la Declaración de las Naciones Unidas sobre el Medio Humano, aprobada el 16 de junio de 1972 en Estocolmo.

Paralelamente a la Cumbre de la Tierra, representantes de organizaciones no gubernamentales (ONGs) realizaron un Foro Global en el cual se elaboraron tratados y se denunciaron públicamente políticas de fuerte impacto ambiental, producto de las actividades de muchas empresas, generalmente multinacionales; asimismo, se confeccionaron varias listas de tecnologías y productos tóxicos y se abogó por la completa participación democrática de las mujeres y de los pueblos indigenas en los procesos de toma de decisiones y manejo de recursos, subrayándose su importante rol en la preservación de ecosistemas.

Se creó igualmente la Comisión de Desarrollo Sostenible (CDS), encargada del seguimiento, en todos los ámbitos: internacional, nacional y local, de los compromisos adquiridos a partir de la Cumbre de Río de Janeiro y se aprobó un programa de trabajo para los siguientes cinco años, centrado en la integración del medio ambiente a los diferentes sectores económicos, siendo lógicamente el turismo uno de ellos. Los temas que la CDS trató en su última reunión fueron: las iniciativas de turismo sostenible por parte de la industria; la influencia en el comportamiento del consumidor para promover el turismo sostenible; la promoción de un desarrollo soste. nible a través del turismo, salvaguardando la identidad de las culturas locales $y$, por otro lado, protegiendo el medio ambiente y previniendo los impactos del turismo en las regiones de costa.

Blaikie y Brookfield ${ }^{32}$ se integran al grupo de autores que trabajan el concepto de ecología política para explicar cómo el contexto político y social, manifestado en el vaivén de las relaciones de poder, determina la forma de explotación de los recursos dentro de un ecosistema. De manera específica lo hacen Peluso ${ }^{33}$ en Indonesia, Painter $y$ Durham ${ }^{34}$ para el contexto latinoamericano en general $y$, más concretamente, Schmink y Wood ${ }^{35}$ para la Amazonía brasileña.

El aspecto consciente y racional de la utilización de los recursos por parte de las comunidades rurales tradicionales es resaltado por Schmink ${ }^{36}$, en tanto que Stonich ${ }^{37}$ recalca que estas sociedades no actuarían guiadas ciegamente por sus costumbres culturales para mantenerse en armonía con el entorno natural o, en el caso opuesto, para degradarlo, sino que la forma adoptada por ellas para la explotación de los recursos serían básicamente resultado de decisiones político-económicas relacionadas a situaciones de poder, al igual que lo hacen los individuos de las sociedades modernas.

Rocheleau ${ }^{38}$ insiste asimismo en las diferencias existentes en estas tomas de decisiones, vale decir en la manera en que la gente, comunidades,

32 P. Blaikie y H. Hrookfokl, eds. "The Degradalion of Comnon Property Resources: Common Property Resources and Degradation Worldwide". En Land Degradatson and Sockety. London, Methuen, 1987: 186-196, cit. en Stronka, ep cit: 20, 166.

33 Nancy Peluso. Rich forests, Poor People Resoutce Control and Resustance in tawa. Berkeley, University of Califomia Press, 1992 , cit. en Stronza, op, cit: 20. 180.

34 Michael Painter $y$ William $\mathrm{H}$. Duhalm, eds the Sectal Causes of Envronnentat Destruction in Latin dimerica. Ann Arbor, University of Michigan Press, 1995, cit. en Stronza, op cit: 20,179

35 Marianne Schmink y Charles $\mathrm{H}$. Wood, eds. Coniested frontiers m Amazonia. New York, Columbia University Press, 1992, cit. en Stronza, op. cit.: 20, 183.

36 Marianne Schmink. "The Socioeconomic Matrix of Deforestation- En L. Arizpe, P. M. Stone, and D. C. Major, ods. Population and Environment: Rethinking the Dehale. Westview Press, Boulder, 1994: 253-275, cit en Stronza, op. ctt: 21, 182-183.

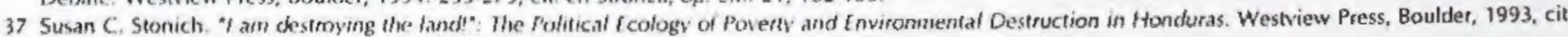
en Stronzin, op cit. 21,184 .

38. Diane Rocheleau, Barbara Thomas-Slayler yster Wangari, eds. Temmist Political fcology: Cilobal Issues and Local Experiences. New York, Routledge, 1996; Dianne Rocheleau. "Cender and Biodiversily: A Ferninist Political Ecology Perspective". En IDS Bulletin 26, 1995: 9-16, cit. en Stronza, op. cit.: 21, 181-182. 
familias u hogares interactúan con el medio ambiente y utilizan los recursos, diferencias que -según Schmink ${ }^{39}$ - estarían directamente relacionadas con los roles de género construidos culturalmente, y que varían de acuerdo con la edad, etnia, riqueza, forma de vida y algunos otros factores. Por lo tanto el turismo afectaría a los individuos dentro de las comunidades y dentro de los hogares en forma diferente, $y$ son estas diferencias las que en última instancia afectarían a la conservación o degradación de los recursos naturales.

Las relaciones de poder entre los diversos grupos de una sociedad, sean estas de tipo económico, social o de género, intervienen en las políticas turísticas vinculadas con la disminución de la pobreza y el desarrollo sostenible. Con ello surge un juego de intereses entre agentes del Estado, operadores turísticos y residentes locales que ineludiblemente afecta la forma de explotación de los recursos en la localidad receptora. En este sentido, frente a lo que varios autores como $\mathrm{Yu}$ et al. ${ }^{40}$ y Bookbinder et al. ${ }^{41}$ han anotado sobre los pocos beneficios locales y de conservación observados por el turismo, Honey ${ }^{+2}$ expresa la importancia de la participación de las comunidades locales como planificadores y dirigentes de su propia empresa turística, mas no de una manera impuesta normalmente después del hecho y típicamente para presentar a la comunidad como un despliegue cultural.

Por otro lado, la conformación de asociaciones entre varias comunidades locales con agencias gubernamentales, organizaciones no gubernamentales y compañias privadas de turismo a fin de planear estrategias de ecoturismo y crear nuevas atracciones para visitantes es vista por Eadington y $\mathrm{Smith}^{43}$ como la evidencia efectiva de la participación local en proyectos turísticos de desarrollo $y$ sostenibilidad. El caso estudiado por Susan Stonich ${ }^{44}$, aplicando el marco de ecología política para el desarrollo del turismo en Honduras, es una confirmación de ello: cuando los residentes locales tienen más autoridad para decidir sobre el manejo de los recursos, los niveles de conservación se alteran positiva o negativamente, debido a que son estos residentes locales quienes más a menudo usan directamente los recursos decidiendo, por ejemplo, si una especie de guacamayo se caza o se protege como atractivo turístico, o si una hectárea de bosque se quema para hacer una chacra o se mantiene para crear un sendero para los visitantes.

A través de la observación de las diferentes formas y motivaciones por las que los pobladores de los sitios anfitriones se ven involucrados en el trabajo turístico, puede saberse cómo esa participación afecta el uso de recursos. Claudia Dary ${ }^{45}$, antropóloga guatemalteca, ofrece un análisis conceptual que permite entender la compleja relación establecida a partir de tres elementos fundamentales: etnia, género y biodiversidad, en comunidades indígenas de Centroamérica. El género, como bien expresaron Swain ${ }^{46}$ y Wikinson ${ }^{47}$, es una variable social importante para establecer la participación de los integrantes de una comunidad anfitriona en el turismo, es decir en qué tipos de actividades se desempeñará una mujer y en cuáles otras un hombre. Por su lado, Levy y Lerch ${ }^{48}$ añaden a esta diferenciación de roles en la actividad turística, las diferenciaciones en las condiciones de trabajo de uno y otro sexo, así

39 Schmink. Sustainable Devetopment with Local Populations in Protected Sites: A Comparative Research Program. Florida, MERGE Program, University of Flosida. Funding Proposal to the North-Soulh Center, 1996, cit en Stronza, op. cit: $21,183$.

40 W. Douglas $Y_{u}$, Thomas Hendrickson y Ada Castillo. Ecotourism and conservation in Amazonian Peru: Short-term and long-lerm challenges". En Environmental Conservation 24, 1997: 130-138, cit, en Sironza, op. cit: 22, 186.

41 Marnie P. Bookbinder, Eric Dinerstein, Arun Rijal, Hank Cauley y Arup Rajouria. "Ecotourism's Support of Biodiversity Conservation". En Conservation Biology 12, 1998: 1399-1404, cit. en Stronza, op. cit.: 22, 167.

42 Martha Honey. Ecotourism and Sustainable Development: Who Owns Paradise? Washington, Island Press, 1999, cit. en Stronza, op. cit.: 22, 175.

43 William R. Eadington y Valene L. Smith, eds. Tourism Afternatives: Potentials and Problems in the Development of Tourism. Phitadelphia, University of Pennsylvania Press, 1992, cit en Stronza, op. cit: 22, 171

44 Susan Stonich. "Political Ecology of Tourism". Annals of Tourism Research 25, 1998: 25-54, cit. en Stronza, op. cit.: 22, 184.

45 Claudia Dary, coord. Cénero y biodiversidad en comunidades indigenas de Centroamérica. Guatemala, FLACSO, 2002.

46 Margaret Byme Swain. "Gender Roles in Indigenous Tourism: Kuna Mola, Kuna Yala, and Cultural Survival". En V. Smith, ed. Hosts and Guests: The Anthropology of Tourism, V. Philadelphia, University of Philadelphia Press, 1989: 83.104; Margaret Byme Swain. "Cender in Tourism", En Annals of Tourism Research 22, 1995:247.266, cit en Stronza, op cit: $23,184$.

47 Paul F. Wilkinson y Wiwik Pratiwi. "Gender and Tourism in an Indonesian Village". En Annals of Tourism Research 22, 1995:283-299, cit. en Stronza, op. cit:: 23, 186.

48 Diane E. Levy y Patricia B. Lerch. "Tourism as a Factor in Development: Implications for Gender and Work in Barbados". En Cender and Society 5, 1991: 67-85, cil. en Stronza, op cit.: $23,176$. 
como De la Cadenat9 y Kinnaird et al. . $^{50}$ lo hacen para señalar la forma en que se recibe a los turistas.

Sin embargo, no siempre las condiciones en las cuales se desenvuelve el turismo son apropiadas para las comunidades. Ashley y $\operatorname{Roe}^{51}$ advierten sobre los distintos desafíos y limitaciones que deben superarse para no caer en el riesgo de convertir en fracasos los esfuerzos realizados para incentivar la participación de las comunidades rurales en el desarrollo del turismo.

El ecoturismo sucle presentarse como una forma de turismo alternativo basado en la observación de la naturaleza, pero sus implicancias no son tan evidentes. No es sinónimo ni de vida silvestre ni de naturaleza, tampoco es una suerte de turismo de aventura en el que se pueda encontrar un fuerte componente de agresividad. A menudo es relacionado con el turismo comunitario o el turismo cultural. Su relativo bajo impacto, además, es reconocido como elemento coadyuvante para la conservación de los bosques en comparación con otras actividades como la caza, tala de madera, minería o agricultura ${ }^{52}$, sugiriéndose incluso las ventajas del ecoturismo, toda vez que ayudaría a proteger y revivir las prácticas y creencias tradicionales que de otra forma pudieran haberse perdi$\mathrm{do}^{53}$, al mismo tiempo que incita al desarrollo y a nuevas formas de prácticas sociales y culturales ${ }^{54}$.

The International Ecotourism Society, TIES, considera al ecoturismo como un viaje responsable a áreas naturales que ayuda a conservar el ambiente $y$ al bienestar de la gente ${ }^{55}$. En una de sus publicaciones ${ }^{56}$, los trabajos recopilados permiten observar la problemática del ecoturismo a nivel mundial, caracterizándola como una actividad en cierto nivel de desarrollo y con implicancias tanto en la conservación del ambiente o espacios naturales como en la manera en que es ejercida (responsabilidad social de los actos desde los turistas). Se balancean así los principios del ecoturismo entre la actividad del turismo, la conservación y el respeto cultural. En un segundo volumen ${ }^{57}$ de la TIES se reconocen claramente los beneficios del ecoturismo practicado de acuerdo a principios fundamentales en relación a la conservación y al desarrollo sostenible en distintas partes del mundo.

Siguiendo la misma tónica, Epler Wood ${ }^{58}$ presenta, con ocasión de las celebraciones del Año Internacional del Ecoturismo 2002, la primera edición de un trabajo que reúne experiencias ecoturísticas desarrolladas exitosamente en distintas partes del mundo dentro del marco de las políticas, principios y prácticas de sostenibilidad. Aquí, el ecoturismo es asumido en una doble acepción: como uno de los componentes del turismo sostenible basado en la observación del turismo de naturaleza, con componentes naturales y culturales, y como el segmento del mercado turístico en más rápido crecimiento que opera básicamente con medianas y pequeñas empresas, centradas en el guiado y alojamiento de grupos reducidos de turistas en áreas naturales, utilizando material interpretativo y guías locales.

El arquitecto mexicano Ceballos-Lascurain ${ }^{59}$ identifica el ecoturismo como la forma de viajar que implica el traslado a entornos naturales vírgenes cuyo objetivo primordial es la interiorización de la experiencia de encontrarse en ambientes

49 M. de la Cadena. "Las mujeres son más indias: elnicidad y gènero en una comunidad del Cusco". En Revista tindina 9. Cusco, CBC, 1991: 7-29.

50 Vivian Kinnaird y Derek Hall, eds. "Conclusien: The Way Forward". En Tourism A Gender Arlalysis, Sussex, Wiley, 1994: 210-216, cit. en Stronza, op. cit.: 23, 176.

51 Carolin Ashley y Delys Roe. Enhancing communty imvolvement in witdite Tourism Issues and Challenges, 1998.

52 Martha A Groom, Rolsen D. Podolsky y Chatles A. Munn. "Tourism as a Sustained Use of Wildlife: A Case Study of Madre de Dios, Southeastern Peru"- En J. G. Robinson and K. H. Redford, eds. Neotropical Widdite Use and Conservation. Chicago, University of Chicago Press, 1991: 393-412, cit. en Stronza, op. Cit.. 13, 174.

53 Pierre van den Berghe. The Quest tor the Othere Ethnic Tourssm in San Cristobal, Mexico. Seatle, Universily of Washington Press, 1994, cit. en Stronza, op. cit.: 13. 185 .

54 Regina Bendix. "Tourism and Cultural Displays: Invenling Traditions for Whom?". En foumal of American folklore 102, 1989: 131-146, cit. en Sironza, op. cit. 13. 166

55 Martha Honey. Ecolourism and Sustamable Develoment Who Owns Paradisep Washington, Island Press, 1999; Willian R. Eadinglon y Valene L. Smith, eds. op cil:; Deirdre Evans-Prilchard. "How 'They' See 'Us'. Native American Images of Tourists". En Anmals of Tourism Research 16, 1989: 89-105, cit. en Stionza, op cit: 13,171; Marie Francoise Lanfant, Joln B. Allcoch y Eslward M. Bruner, eds, International Tourisn: Identity and Change. London, Sage, 1995 , cit. en Stron 2d, op. cit.: 13, 176 .

56 Kris Lindleerg y Donald E. Hawkins. Ecotoursm. A guide for planners and managers, vol. 1, 1a ed., North Benington, 1993.

57 Kreg lindlserg, Megan Epler Wood y David Engeldrum. Fcotourism. A guide for planners and managers, vol. 2, 1 a ed. North Benington, 1998.

58 Megan Epler Wood. Ecotourism: principles, practices \& policies for sustainability, 1a ed. Parls, UNEP, 2002.

59 Cit. en Stephen Wearing. John Neil and Penny Figgis. Ecolurismo Impacto, tendencias y posibilidades, Madrid, Sinlesis, $1999: 26$. 
naturales en estado puro. Pero Erlet Cater ${ }^{60}$ señala ya de manera abierta las confusiones a las que se prestan las definiciones dadas para el ecoturismo.

Algunos académicos ${ }^{61}$ aseguran que si el turismo no es monitoreado ni regulado particular y convenientemente, las áreas de reserva naturales y la vida silvestre de la Tierra corren riesgo de extinguirse $y$, no obstante las bondades atribuidas al ecoturismo, la suspicacia de los especialistas en temas de desarrollo no logra ser aplacada en tanto los efectos del impacto de la actividad ecoturística empiezan a aparecer. $A$ ellos ${ }^{62}$ les preocupa que el turismo sea una suerte de imperialismo interesado en dominar las instituciones tradicionales, destruir las culturas locales y patentizar material genético; afirman que el turismo puede codificar la cultura de las comunidades rurales y hacerla perder su significado ${ }^{63}$.

Ante tales inseguridades, Wearing et al. ${ }^{64}$ elaboraron sus ideas de manera exhaustiva y con anplitud de criterio a fin de proporcionar completa cobertura sobre el ecoturismo, analizando sus aspectos positivos y negativos. Más que intentar dar una definición del término, recalcan la importancia del trabajo previo y consciente de planificación para el desarrollo y la gestión del ecoturismo, traducido en el viaje a zonas relativamente vírgenes o espacios naturales protegidos, fomentando la conservación del entorno en la zona de clestino, la gestión de los recursos y contribuyendo positivamente al bienestar de las comunidades receptoras, a través de vínculos entre la industria turística, las comunidades locales y las zonas protegidas. Ello supone, entre otras cosas, para los autores, valorar la naturaleza desde una perspectiva histórica y filosófica, donde la relación y la interacción entre el hombre y la naturaleza revelan un cambio en la escala de valores (experiencia ecoturística).

Se hace además un repaso sobre las exigencias para los gobiernos y las empresas interesados en implementar el turismo como actividad alternativa frente $\mathbf{a}$ industrias tradicionales (silvicultura o minería) y cuestionables por su sostenibilidad, tales como la necesidad de una estrategia global en concordancia con marcos legales, la consulta e involucramiento de las comunidades locales y la elaboración de planes eficaces para la gestión de zonas protegidas.

Otra materia de análisis para los autores es el conflicto entre conservación $y$ uso que se evidencia con mayor fuerza en las zonas protegidas, el cual aparece cuando surge la idea de espacios protegidos y reservas equivalentes. La preocupación de los que abogan por la conservación al parecer radica en la forma cómo se ha de consenvar y no precisamente en el hecho de hacerlo o no. Así, el ecoturismo como estrategia de desarrollo sostenible, según los autores australianos, se orientaría cada vez más a formar parte de una filosofía politica para los gestores de zonas protegidas y para las agencias de conservación que observan en esta actividad una manera práctica de sentar las bases para una protección continuada de estas y que, a diferencia de las otras prácticas turísticas focalizadas en la naturaleza, incluye dos elementos claves: interpretación y educación; pues el visitante al formar parte de esta experiencia no so. lo observa un entorno determinado sino que se siente parte de él, interioriza asi su valor, aumenta su grado de comprensión sobre el lugar visitado lo que, en el mejor de los casos, crea una actitud de conciencia más clara y amplia frente a los entornos naturales, nativos y comunitarios.

60 Erlet Cater and Cwen Lowman, eds Ecotoumsa A sustainable optiont West Sussex, fohn Wiley and Sons, $1994:$ 3-17.

61 Joan Giannecchini. "Ecotourism: New Partnets, New Relationships". En Conservation Biology 7, 1993: 429-432, cit. en Stronza, op. cit: 13, 173; R. 5. de Groot. "Tourism and Conservation in the Galapagos Islands". En Biological Conservation 26, 1983 291-300, cit. en Stronza, op. cit.: 13, 170; K. Brandon. "Ecoturismo y conservación: una reseña de temas claves". En the World Bank: Environment Department Papers, no $33,1996$.

62 Edward M Bruner "Of Cannilals, Tourists, and Etlinographers". En Cultural Amthropology, 1987; 438-445, cil. en Stronza, op. cit.: 13, 167; Mark C. Mansperger. "Tourism and Cultural Change in Small-Scale Societies". En Human Organization 54, 1995: 87-94, cit. en Stronza, op. cit: 13 , i77; Nuñez Ir. y Theron A. -Touristic Sludies in Anthropological Perspective". En V. Smith ed. Hosts and Guests. The Anthropology of Tourism, 2a ed. Philadelphia, University of Pennsyl. vania Press, 1989: 265-279, cit. en Stronza, op cit. 11, 179; Pierre Rossel. Tourism and Cultural Minorities: Double Marginalization'- En Survival Strafegies. Copenhagen, Document IWGiA, 1988: 1-20, cil en Stronz,1, op cit: 13, 182; C. Michael Hall. "Ecotourism in Australia, New Zealand and the South Pacific: Ap. propriate Tourism or a New form of Ecological Imperialism?". En Ertet Cater and Cwen Lowman, eds. Ecotourism. A sustainable option? West Sussex, John Wiley and Sons, 1994: 137.157.

63 D. J. Greenwood "Culture by ilıe Pound. An Anthropological Perspective on Taurism as Cultural Commoditization". En V. Smith, ed., op. cit.: 171-185, cit. en Stronza, op cit: $13,173.174$.

64 Stephen Wearing, John Neil and Penny Figgis. Ecolurismo. Impacto, tendencias y posibuhdactes. Madrid, SIntesis, 1999. 
Mediante ejemplos específicos sobre experiencias ecoturísticas en Costa Rica a nivel local, se pone en evidencia la disyuntiva entre desarrollo y conservación del entorno natural cuando se intenta impulsar la autosuficiencia económica en el seno de una comunidad que cuenta con pocos ingresos; $y$, en un ámbito nacional, los que describen mecanismos empleados en Australia para vincular a las distintas instituciones conservacionistas y de gobierno en el cumplimiento de los objetivos del ecoturismo demuestran que el predominio de las ideologías económicas de corte racionalista entre los estamentos gubernamentales es hostil a la protección del espacio natural, generándose -por lo mismo- tan solo un apoyo marginal hacia dichas zonas.

De igual manera, en la obra, no dejan de tratarse aspectos fundamentales para el interés empresarial tales como la comercialización del ecoturismo que frecuentemente se presta a confusiones y controversia por los distintos intereses que se tratan de compaginar: por un lado el de los espacios protegidos y el de las comunidades locales $y$, por el otro, los de la industria turística, describiéndose además el mercado ecoturístico, las características de los ecoturistas y sus motivaciones, las cuestiones sobre sostenibilidad, haciendo hincapié en la necesidad de una normativa adecuada para regular las actividades del sector privado y lograr una gestión responsable de los espacios protegidos. Asimismo, el potencial del ecoturismo como modelo de desarroilo sostenible requiere de marcos estructurales que permitan evaluar los beneficios económicos y los mecanismos mediante los cuales estos puedan constituirse como incentivos suficientes para que las comunidades locales opten por la conservación. Frecuentemente dichos beneficios quedan contrarrestados, desde el punto de vista de las comunidades locales, por problemas como la irrupción de turistas, la existencia de mayores desigualdades en cuanto a ingresos dentro de cada comunidad local y entre unas comunidades y otras, el aumento de la contaminación, la apropiación de los beneficios por parte de personas ajenas al colectivo y la subida de precios en el ámbito local65.

Seduce particularmente al lector la capacidad de estos autores australianos para reconocer que el ecoturismo forma parte de una nueva orientación filosófica política, es decir de una nueva visión de la realidad, lo cual inevitablemente conduciría a una nueva forma de manejo de los recursos. González de Molina y Martínez Alier ${ }^{66}$ coinciden en este punto cuando hablan del cambio epistemológico, capaz de restituir la unidad que nunca debió perderse entre el género humano y la naturaleza, resquebrajada por la separación artificial y sustentada en la vieja idea, que tomó cuerpo con la llustración, de que los seres humanos debían y podían dominar la naturaleza en su propio beneficio ${ }^{67}$. Además proponen hacer una interpretación del pasado en términos no únicamente de relaciones entre seres humanos, sino de relaciones entre los seres humanos con la naturale$z a$, utilizando como indicador principal, para juzgar a las civilizaciones, el carácter sostenible del bienestar material alcanzado por ellas, es decir qué tan capaces fueron de hacer perdurar este bienestar en el tiempo, en lugar de solo considerar si lo alcanzaron o no.

Frente a estas exigencias, se percibe una situación de crisis que requiere al mismo tiempo una salida. Algunos opinan que se trataría de una crisis ecológica, otros dirían que sería moral pero siempre, en todas ellas, se asumirá su carácter integral u holístico por considerarse que atañe directa y concretamente a todos los aspectos de la vida humana ${ }^{68}$.

Al respecto, la ecología profunda es una de las corrientes de pensamiento del ecocentrismo ${ }^{69}$ que empieza fundamentalmente con el filósofo

65 Wearing et. at. op cil: 19-20

66 Manuel González de Molina y Juan Martinez Alier, eds. Historia y ecologia Madrid, Ayer, 1993: 12.13; Juan Martinez Alict, "La interpreución ecologista de La historia socioeconómica: algunos ejemplos andinos". En Henrique Untano, comp. Mfodernidad en los Andes. Cusco, Centro Bartolome de las Casas CaC, 19go: 255-279.

67 El filbsolo empirista escorés John Locke (1632-1704) expreso la herencis moderma del mundo nalural, en su Un ensayo referente a la comprension humand, al afimur que todo lo que habja en la naturaleza era desperdicio hash que las personas lo irnnsformaloan en cosas de valor utilizables, cit. en Wearing et al., co. cit.: 36

68 Miguel Polo Ángel Santillana. Ĺtica y crisis moral, 1* ed. Limi, Perú texios edilores, 1996

69 Desde una perspectiva ecocentrista, se señala la necesidad de una feforma fundamental en todos los ambilos: social, economico y educativo: $\gamma$, en definitiva, una reorientación completa de la socieclad tal como se la conoce hoy en día. 
noruego Arnae Naess ${ }^{70}$, fuertemente influido por la ecología y la filosofía de Spinoza (16371677). Es una visión del mundo global que se basa en una concepción holística de la naturaleza en la que el yo del ser humano se encuentra intrínsecamente conectado con todas las formas de la naturaleza; por lo tanto, no existirian límites verdaderos que separen al individuo de las demás formas de vida (una sola ontología), siendo la naturaleza una extensión del mismo ser humano: En consecuencia, corresponde respetarla y estar al servicio de los intereses comunes de todas las especies.

Pero no todas las posiciones que se adjudican a sí mismas el prefijo eco estarian en condiciones de aceptar las propuestas ambientalistas. Los autores que, como Whelan et al. ${ }^{71}$, se declaran defensores de la ecología humana, presentan una crítica al ambientalismo radical por considerarlo una ideología fundamentalista que promueve el control de la población y sitúa al hombre, a la ciencia y a la tecnología como enemigos del planeta. Señalan además que esta postura ecocéntrica radical desestima hechos científicos y la realidad objetiva, desafiando la concepción antropocéntrica judeocristiana de la persona humana y su adecuada relación con el mundo.

Como quiera que el desarrollo se genere, ecocéntrica o antropocéntricamente, implica condiciones globales que deben integrarse. Amartya $\operatorname{Sen}^{72}$, en relación a las condiciones de vida en un mundo desarrollado y teniendo en cuenta la profunda diversidad de los seres humanos, sostiene que el igualitarismo en un campo conlleva al rechazo en otro, por lo cual un nuevo examen de la desigualdad valdría la pena si el objetivo se centra en la capacidad que tienen las personas para alcanzar metas y funcionamientos que consideran valiosos $y$, en general, para conseguir la libertad de promover los fines que valoran; jun- to a aspectos de incentivos y eficiencia con relación a la desigualdad, pues la evaluación del grado de igualdad no puede ser separada de la consideración de la eficiencia, teniéndose que examinar además las circunstancias en las que ambas pueden entrar en contradicción.

Sin embargo, el desarrollo no es, para el ganador del Nobel en Ciencia Económica $1998^{73}$, el desarrollo del mercado. Él afirma que el mundo actual se caracteriza por una opulencia sin precedentes, inimaginable incluso hace cien o doscientos años, y que a pesar de los logros políti$\cos$ y democráticos, de haberse creado las condiciones sanitarias para garantizar una ciclo humano de vida más largo, de la retórica imperante en materia de derechos humanos, de la cercanía y ahorro de tiempo en las comunicaciones, todavía existen notables privaciones, miseria y opresión en el mundo. La superación de estos problemas debería considerar ciertas libertades instrumentales fundamentales para decir verdaderamente que se habita en un mundo desarrollado, entre las cuales se encuentran las oportunidades económicas, las libertades políticas, los servicios sociales, las garantías de transparencia, la seguridad protectora en conjunción con la libertad individual como compromiso social, reconociendo el lugar fundamental que esta ocupa y la influencia de los factores sociales en el grado y el alcance de esa libertad.

Retomando nuevamente la discusión turística y, con ello, la del ecoturismo, la opinión de Henrique Urbano, agudo e ingenioso investigador, muy familiarizado con los temas turismo, patrimonio, desarrollo y modernidad ${ }^{74}$ en los Andes, no podría dejarse de discutir. Su apreciación sobre el conflicto generado con la incorporación de los recursos culturales al mercado ${ }^{75}$ es semejante al suscitado con la explotación de los recursos naturales, pues en ambos casos el patrimonio (cultural y natural) se destina al comercio turístico.

\footnotetext{
70 Cit. en Wearing ef al. op. cat: 41.

71 Robert Whelan, Joseph Kirwan y Paul Hafiner. fcologia humana respuesta cristiana al ambientalismo radical, Santiago de Chile, Nałura, 1996.

72 Amartya Sen. Nuevo examen de la desigualdad. Madrid, Alianza, 1995.

73 Amartya Sen. Desarrollo y libertad Barcelona, Planela, 2000.

74 Henrique Urbano. Moderuidad en los Andes. Cusco, Centro Bartolome de las Casas CBC. 1990; Tradición y modernidad en los Andes. Cusco, CBC, 1992. Henrique Urbano. Turismo y Patrimonio 1. Lima, Universidad de San Martín de Porres, 2000.

75 Henrique Urbano. Turismo y Patrimonio 1. Lima, Universidad de San Martin de Porres, 2000: 13.25.
} 
Guiado por su alumna, Alejandra Arellano ${ }^{76}$, Urbano se instruye en lo que él considera como últimas novedades respecto del uso turístico del patrimonio, los planteamientos ingleses ${ }^{77}$, sin siquiera intuir acaso que sus escritos sobre tradición y modernidad de una década atrás ya estaban abordando implícitamente el conflicto patrimonio-mercado ${ }^{78}$. La conciencia fragmentada es, para el sociólogo portugués, lo que corresponde a la mirada turística, y el consumo que el turista hace del patrimonio es lo que decide el destino patrimonial: "En este sentido, la conciencia fragmentada del individuo contemporáneo pondría entre paréntesis la continuidad histórica y el turista se ahorra el discurso de la herencia patrimonial"79.

¿Por qué se pronuncia solo desde una perspectiva convencional del hecho turístico? ipor qué obvia referirse a las relativas nuevas formas de hacer turismo que en definitiva también involucran una forma de usar el patrimonio? iY por qué insiste tanto en el patrimonio como insinuación de permanencias retrógradas y dañinas, como si todo lo que procediese de él tan solo fuese sinónimo de atraso u obstáculo para el progreso? Su concepción del cambio como actitud mental y de comportamiento le sinve de apoyo para hablar de modernidad, especialmente en el ámbito peruano, pero ipor qué esta necesariamente tendría que ser negación del pasado?, ¿y por qué no podría asumirse el cambio en términos de replanteamientos y redefiniciones que incluyan tanto elementos de la tradición y de la modernidad, en una suerte de coladera que permita rescatar aquellos viejos elementos pero positivos, y junto a ellos incorporar los buenos nuevos elernentos de la modernidad?

Lo que Urbano tampoco llega a decir es si considera acertada, o no, la comercialización del patrimonio y bajo qué términos. Solo describe el hecho.
Sus afirmaciones respecto de la fragmentación de la mirada turística no coinciden necesariamente con lo que se estaría reflejando a través de la experiencia ecoturística, cuyo propósito primordial es generar conciencia y patrones de conducta para la valoración y conservación del entorno natural, vale decir del mismo patrimonio. Esto es especialmente importante para realidades como la peruana donde la gente no está educada con una conciencia patrimonial, ni individual ni colectiva, $y$ donde, a ciencia cierta, no se ha definido un proyecto nacional común. ¿Cómo, entonces, podrían proporcionarse o generarse los elementos necesarios para que los individuos logren su propia conciencia del patrimonio en caso de no creerse en o querer la codificación de la cultura?

Por su parte García Canclini ${ }^{80}$ también se refiere al patrimonio tan solo como cultural. La reformulación que plantea de este en términos de capital cultural común es de gran ayuda para los problemas concernientes a uso y conservación, pues permite entender el patrimonio como un proceso social en constante reformulación. La apropiación de los saberes de cada sociedad, a través de las escuelas y los museos, se produce de forma diferente y desigual entre los diversos grupos, según sus posibilidades ${ }^{81}$. Si existen diferentes formas de apropiación del patrimonio, entonces también existe una capacidad diversa de relación con él82. Ni la historia ni los bienes atribuidos formalmente a una sociedad realmente pertenecen a todos quienes la integran. La realidad latinoamericana, a pesar de haber desarrollado algunos rasgos -0 remedos como lo especifica Urbano- de modernidad, en esencia no ha perdido sus rasgos tradicionales. El proceso social latinoamericano es especialmente complejo y contradictorio; por lo tanto, insistir en la oposición tradición versus modernidad no parecería ser la solución adecuada a los problemas

\footnotetext{
76 Alexandra Areilano. "Echando una mirada al Iema del patrimonio". En Henrique Urbano, ed. Turismo y Patrimonio 2. Lima, Universidad de San Martin de Porres, 2000: 101-114.

77 John Urry, The Tourist Caze. London, Sae, 1990

78 El tratamiento francés del patrimonio por oposición a la subversión rellejada por la postura inglesa en el mismo tema es expuesto por Arellano, op. cit. 2000. La primera refleja una postura tradicional y la segunda es vista como moderna.

79 Henrique Urbano. Turismo y Patrimonio 1. Lima, Universidad de San Martin de Porres, 2000: 23.

80 Néstor Garela Canclini. Culturas hibridas, Estrategias pafa entrar y salir de la modernidad. Buenos Aires, Editorial Paidós, 2001 : 187.

81 Este es un principio general en las investigaciones sobre las leyes sociales antropológicas y sociológicas de la difusion cultural (Pierre Bourdieu y lean Claude Passeron. La reproducción. Elementos para una teorla del sistema de enserlanza. Barcelona, Laia, 1977 y P. Bourdieu y Atan Darbel. Lamour de Fart. Les musées d'art evoréennes et leur public) enunciado por Garcla Canclini, op. cit.: 186.

82 Garcla Canclini plantea la reformulación del patrimonio en términos de capital cultural común, ya que permite representarlo como un proceso social en constanle reformulación. Como capital, el patrimonio se convierte, produce rendimienios y es apropiado desigualmente por los diversos sectores, op. cit.: 187.
} 
culturales, y por ende de desarrollo, en esta sociedad. Un verdadero proceso social de creación cultural en Latinoamérica debe incluir lo arcaico, lo residual y lo emergente de una sociedad $^{83}$, pues esto indica asumir las contradicciones de los tiempos contemporáneos.

Concretamente, el ecoturismo en el Perú podría ser una alternativa para el desarrollo, teniendo en cuenta el asombroso potencial de recursos naturales y culturales que posee. Se han dado algunas iniciativas gubernamentales sobre acuerdos y preparación de documentos para reuniones oficiales a nivel mundial (ej. Cumbre Mundial del Ecoturismo o Cumbre Mundial sobre el Desarrollo Sostenible) pero, en realidad, la preocupación estatal por la elaboración de un plan turístico sostenible sustentado en el ecoturismo aparentemente no pasa de concretarse en informes técnicos de archivo para presentarse en eventos internacionalmente oficiales en razón de una mera formalidad ${ }^{84}$. Los escasos esfuerzos por abordar esta realidad vienen generalmente de algunos empresarios particulares con cierta perspectiva de desarrollo y mentalidad abierta, de agencias internacionales o de investigadores.

Para observar el impacto ejercido por el ecoturismo en las sociedades tradicionales y cómo este puede alterar la interacción de la población local con su entorno natural, Amanda Stronza ${ }^{85}$ estudia el caso concreto de Posada Amazonas ${ }^{86}$, explicando sus planteamientos sobre el mismo en base a las nociones de cambio, progreso y desarrollo, y en el marco general de los principios de ecología política y sostenibilidad. Mejor que anteponer el análisis económico y las transacciones de mercado en la comprensión de las transformaciones sociales de las culturas locales tradicionales por obra y magia de las actividades turísticas, la tesis de Stronza presta atención al factor participativo con arreglo a fines, con lo cual se reconoce la vital importancia del rol comunitario en los múltiples aspectos del ecoturismo, desde su concepción como idea y en todo su proceso de planificación, venta, manejo y evaluación.

Asimismo, información sobre aspectos culturales y tradicionales ${ }^{87}$, históricos y socioeconómicos ${ }^{88}$ de los ese'eja puede hallarse en autores como María Chavarría ${ }^{89}$, Miguel Alexiades ${ }^{90}$ y Peluso ${ }^{91}$, entre otros.

El proyecto ecoturístico Casa Matsiguenka en el Parque Nacional del Manu es otra iniciativa local que recibe asesoramiento y apoyo del Fortalecimiento del Sistema Nacional de Áreas Protegidas por el Estado (FANPE) y la Cooperación Técnica Alemana (GTZ). Julia Oh192, en un estudio que constituye un esfuerzo por incorporar elementos cuantitativos a la investigación relacionada con el ecoturismo, analiza el sistema económico tradicional de dos comunidades matsiguenkas, Tayakome y Yomibato, y la influencia en ellas de nuevas formas económicas, especialmente la empresa turística, así como en el Parque Nacional del Manu, obteniendo conclusiones en cuanto a la sostenibilidad de la participación de los matsiguenkas en el negocio turístico.

83 Raymond Williams diferencia entre los elementos que pertenecen al pasado, reconocidos como tales por quienes lo reviven en la aciualidad, casi siempre de un modo deliberadamente especializado (lo arcaico); los elementos que se formaron en el pasado, pero que todavia se hallan en actividad dentro de los procesos culturales (lo residual); y los elementos que designan nuevos significados y valores, nuevas prácticas y relaciones sociales (lo emergente), cit. por Garcia Canclini, op. cit.; 189.

84 UNALM y PromPerú. Primer informe de la situación del ecoturismo en el Perui, ms. Lima, 2002; Diagnóstico del ecoturismo en el Perú y la propuesta de politicas para orientar los beneficios del ecoturismo hacia las poblaciones locales y el Programa Nacional de Turismo Sostenible, a cargo del Grupo Técnico de Turismo Sostenible convocado por Promperú.

85 Amanda Stronza-Rojas. Porque es de nosotros. El ecoturismo comunitario en la Amazonía peruana. Tesis doctoral, ms. Florida, Universidad de Florida, 2000.

86 Albergue ecoturístico en la selva peruana en el departamento de Madre de Dios.

87 Mnislav Zelený. Contribución a la einografia huaraya (ece je). Contribución a la etnografia y clasificación del grupo étnico huarayo (ece ie), Aladre de Dios, Perú. Praga, Universidad Karlova, 1976.

88 Judith E. Vivar A. Los huarayo en el Madre de Dios: una introducción al estudio de cambios socio-económicos y culturales de esta etnia nativa. Lima, Pontificia Universidad Catolica del Perü-Institulo Riva Aguero-Seminafio de Arqueologia, 1977.

89 Maria Chavaría. Eshawakuana, sombras y espirntus. Identidad y armonía en la tradición oral ese'cja, tomos I y II. Lima, Programa Marco de Formación Profesional Tecnologica y Pedagógica en el Perú (FORTE-PE), 2002

90 En una tesis que mancja aspectos de conservación biológica y cultural en el manejo de recursos naturales que hace la población eséeja, la investigación de Miguel Alexiades es de gran interés para el presente estudio por los datos relacionados al uso y conservación de plantas con propiedades medicinales en la selva peruana (mancjo de recursos) (Miguel N. Alexiades, Ethobotany or the ese'eia: Plants, Health and Change in an Amazonian Society. Ann Arbor, Nueva York, UMl Microform, 1999].

91 Daniela M. Peluso. "Varialvilidad y cambio en los nombres personales en una sociedad indigena amazónica". En Amazonia peruana, t. XIV, ${ }^{\circ}$ 28-29, 2003: 103-124.

92 Julia Ohl. ¿El eco-turismo como oportunidad para un desarrollo sostenible? La economía de los matsiguenkas en el Parque Nacional del Manu. Perú. Eschborn. Deutsche Gesellschait für Technische Zusammenarbeit (GTZ), 2004. 
Transcurrida una década desde la Cumbre de la Tierra, los resultados y los compromisos asumidos en ella no son tan drásticos. La revisión de los acuerdos de Río se realiza cada cinco años $y$, muy lentamente, se van produciendo cambios en las actitudes, tanto de los gobiernos como de los habitantes del planeta, respecto de los problemas ambientales centrados actualmente en cuatro pilares: el cambio climático, la destrucción de la flora y la fauna, la superpoblación y la desaparición del ozono. A ello se suman los problemas de conservación, desarrollo y lucha contra la pobreza con énfasis en la participación local.

En enero de 2002, la Secretaría del Convenio sobre la Diversidad Biológica ${ }^{93}$ presentó el Desarrollo de Directrices para un Turismo Sostenible en Ecosistemas Vulnerables, y en Johannesburgo, Sudáfrica (Cumbre Mundial del Desarrollo Sostenible ${ }^{94}, 26$ de agosto al 4 de septiembre de 2002), debían retomarse las preocupaciones pendientes; sin embargo no hubo consenso ni se acordaron medidas de acción concretas, quedando así evidenciadas las consecuencias ingratas de una actividad turística sin planificación ni control, denunciadas ya en 1999 por el Código Ético Mundial para el Turismo: presión insoportable en las especies más frágiles, menoscabo de la diversidad biológica, necesidades de agua y energía que entran en competencia con las de la población local, congestión de los sitios culturales y monumentos más frecuentados, tradiciones locales amenazadas, explotación de trabajadores desarraigados de su pueblo de origen, turismo sexual organizado que a veces implica a niños y niñas.

Por último, la Declaración de Québec ${ }^{95}$ estableció que el ecoturismo debe ser considerado como aquel tipo de turismo especializado en la obsenación y apreciación de la naturaleza, así como de las culturas tradicionales prevalecientes en las zonas naturales; su alta especialización requiere de la organización de grupos reducidos, a cargo de empresas locales que faciliten la interpretación y el aprendizaje que demandan su práctica. Asimismo, el documento ha reconocido oficialmente la importancia del ecoturismo en el cumplimiento de la sostenibilidad turística porque minimiza los impactos negativos sobre el medio natural y sociocultural, apoya a la protección de zonas naturales, generando beneficios económicos locales y para los organismos y autoridades que gestionan estas zonas con objetivos de conservación; al mismo tiempo que constituye una alternativa de empleo y de obtención de rentas en un orden de participación comunitaria, mediante la sensibilización de las poblaciones locales y de los turistas respecto de la conservación de los bienes naturales y culturales.

El protagonismo de las comunidades indígenas locales en las áreas de protección debió ser materia de amplia discusión en el $\vee$ Congreso Mundial de Parques en Durban, Sudáfrica, realizado recientemente, del 8 al 17 de setiembre de $2003^{96}$, para definir así el derecho de los pueblos indígenas en el control y destino de sus territorios, que son áreas prohibidas para las industrias extractivas. La Cumbre Mundial del Ecoturismo en Québec definió claramente la participación imprescindible de las comunidades receptoras durante todo el proceso de planificación e implementación de cualquier proyecto de ecoturismo, en zonas donde se detecta la presencia de grupos locales históricamente arraigados; existiendo, por ello, la necesidad de identificar la propiedad de la tierra a través de mecanismos que establezcan y registren los derechos sobre la misma, reconociendo y mejorando la capacidad de las comunidades para ejercer control sobre la gestión del ecoturismo, de los recursos y de sus beneficios, sea directa o indirectamente y mediante programas de formación y perfeccionamiento. Por otro lado, se da prioridad a las áreas naturales protegidas en el desarrollo del ecoturismo por los fines de conservación que encierra su misma creación y porque constituye una fuente importante de ingresos para ellas.

93 Secretaria del Convenio sobre la diversidad biológica. Diversidad biológica y furismo: desarrollo de directrices para un turismo en ecosistemas vulnerables. Que bec, PNUMA, 2002.

$94 \mathrm{Ver}$ www.un.org/spanislv/conferences/wssd/feature story41.htm, 28.11.2003.

95 Ver www.cinu.org.muleventos/turismo2002/doctos/dec_quebec.htm, 29.11.2003

96 Ver www.sur.iucn.org/vitrina/noticia.cfm?passcodnot $-556,3.12 .2003$. 
No obstante, todavía se encuentran vacíos en la definición del término ecoturismo, sobre todo en lo que concierne al Perú. Los esfuerzos están en ciernes. La idea de esta investigación es aproximarse de la manera más acertada al hecho ecoturístico en la Amazonía peruana, integrando todos sus elementos e implicancias, para lograr así un concepto del ecoturismo representativo y aplicado a la realidad peruana.

\section{METODOLOGÍA}

La obtención de datos y la observación de las prácticas ecoturísticas en las comunidades de Infierno (ubicada en los airededores de la Reserva Nacional de Tambopata) y matsiguenkas de Tayakome y Yomibato en el Manu, junto a los resultados de este proceso, serán analizados y comparados con apoyo del material bibliográfico, documentos oficiales y de archivo histórico inclusive.

Asimismo, se está considerando un intercambio vivencial entre los trabajadores de Posada Amazonas y Casa Matsiguenka (se entiende, miembros de las comunidades) para enriquecer el aprendizaje y conocimiento de ambos hechos ecoturísticos.

Entre las técnicas de investigación para la recolección y producción de datos se emplearán entrevistas, encuestas, observación participante e historia oral.

Con los miembros de las comunidades se establecerá el proceso de entrevista abierta en relación a la información, deseos o expectativas que ellos tienen de los respectivos proyectos, si saben de lo que se trata, si les gustaría trabajar en turismo o de qué manera empezaron a trabajar en esta actividad, si ya tuvieron la oportunidad de hacerlo previamente en otro tipo de establecimientos turísticos y si piensan seguir haciéndolo en el futuro.

Empleando igualmente entrevistas abiertas se quiere conocer la manera en que su participación en el ecoturismo ha modificado sus vidas cotidianas y familiares, a través de lo cual se pretende estable. cer también el impacto generado por el ecoturismo y cuáles son las motivaciones o incentivos que los han llevado a trabajar en él. Se determinará además el tipo de participación de los miembros de las comunidades en ecoturismo, reforzado a través de la aplicación de encuestas en función a las variables de edad, sexo, nivel de educación y etnicidad.

El diálogo abierto, a través de entrevistas, con los miembros de las empresas ecoturísticas (Rainforest Expeditions) y operadores asociados, asesores técnicos o miembros de agencias de desarrollo y fundaciones (FANPE-GTZ) que apoyan a las comunidades en la conducción de estos albergues es asimismo importante para apreciar los juegos e intereses de poder reflejados en la conducción de ambos proyectos.

La impresión de los ecoturistas que visitan los albergues se plasmará en encuestas especialmente diseñadas para ellos, donde será posible detectar el grado de satisfacción que tuvieron por los servicios prestados en cada albergue durante el tiempo de su estadía.

Usando la técnica de observación participante, se podrá conocer mejor los mecanismos de interacción entre anfitriones (miembros de la comunidad) y turistas, apreciando los esfuerzos de los miembros de las comunidades para reflejar rasgos de absoluta autenticidad ante la mirada de los turistas; así como la manera en que estos perciben a dichos miembros prestando servicios en los albergues y si llegan a sensibilizarse con el aprendizaje de los valores medioambientales y culturales proporcionados tras la experiencia ecoturística.

La observación participante al mismo tiempo proporcionará la oportunidad de alternar con los turistas que llegan a instalarse en los albergues, durante los horarios de comida y traslados a los atractivos naturales, haciendo extensible, además, la convivencia con el personal del albergue (cuarteleros, cocineros, mozos, lavanderos, motoristas) y guías en sus propios hogares, en la realización de tareas cotidianas domésticas junto a sus familiares y vecinos de sus respectivas comunidades. Asimismo, empleando historia oral, en algunos casos podrá obtenerse información cualitativa sobre las prácticas tradicionales de estas comunidades. 


\section{DEMOSTRACIÓN}

Esta propuesta de investigación comprende el conocimiento de las realidades locales a través de la obtención de datos y observación de las prácticas ecoturísticas en las comunidades de Infierno (situada en las proximidades de la Reserva Nacional de Tambopata) y matsiguenkas de Tayakome y Yomibato (en el Parque Nacional del Manu), con todo lo cual se pretende configurar un cuerpo de prácticas sostenibles que permitan definir un modelo ecoturístico viable y replicable en el Perú.

Aunque ambos hechos ecoturisticos se localizan en el departamento de Madre de Dios, constituyen casos distintos. Por ejemplo, Posada Amazonas se desarrolla en la periferia de la Reserva de
Tambopata, mientras que la Casa Matsiguenka se encuentra en Cocha Salvador, al interior de la zona protegida del Parque Nacional del Manu. Este factor hace variar las condiciones en que se desenvuelve el ecoturismo para cada caso.

El desarrollo de este estudio comparativo busca, entonces, constatar la forma en que se produce la presencia y participación de las poblaciones locales de infierno y matisguenkas de Tayakome y Yomibato en las actividades ecoturísticas llevadas a cabo por cada una de ellas, describiendo aspectos en relación a los cambios generados a partir de dichas actividades. Aparte de considerar componentes sociohistóricos y geográficos, el esquema básico de trabajo para la demostración estará orientado a desarrollar los siguientes elementos de análisis:

\begin{tabular}{|c|c|}
\hline POSADA AMAZONAS & CASA MATSIGUENKA \\
\hline Gestión y manejo de los recursos antes de 1996 & Gestión y manejo de los recursos antes de 1998 \\
\hline $\begin{array}{l}1 \text { Situación socioeconómica } \\
\text { Pobreza. } \\
\text { Economia de subsistencia. } \\
\text { Comercialización de productos. }\end{array}$ & $\begin{array}{l}1 \text { Situación socioeconómica } \\
\text { Pobreza. } \\
\text { Economía de subsistencia. } \\
\text { Comercialización de productos. }\end{array}$ \\
\hline $\begin{array}{l}2 \text { Actividades económicas: uso dependiente de los recursos } \\
\text { Cazs. } \\
\text { Pesca. } \\
\text { Tala de madera. } \\
\text { Agricultura. } \\
\text { Minería. }\end{array}$ & $\begin{array}{l}2 \text { Actividades cconómicas: uso dependiente de los recursos } \\
\text { Caza. } \\
\text { Pesca. } \\
\text { Tala de madera. } \\
\text { Agricultura. } \\
\text { Minería. }\end{array}$ \\
\hline 3 Impacio: depredación de recursos & 3 Impacto: depredación de recursos \\
\hline $\begin{array}{l}\text { Gestión y manejo de recursos después de } 1996 \\
1 \text { Situación sociocconómica } \\
\text { Integración al mercado laboral. } \\
\text { Número y tipos de empleos. } \\
\text { Ingresos (sueldos, beneficios, ganancias). } \\
\text { Capacitación. }\end{array}$ & $\begin{array}{l}\text { Gestión y manejo de recursos después de } 1998 \\
1 \text { Situaciôn sociocconómica } \\
\text { Integración al mercado laboral. } \\
\text { Número y tipos de empleos. } \\
\text { Ingresos (sueldos, beneficios, ganancias). } \\
\text { Capacitación. }\end{array}$ \\
\hline $\begin{array}{l}2 \text { Uso racional de los recursos } \\
\text { Conservación. } \\
\text { Menos presión solbre ciertos recursos. } \\
\text { Innovación: prácticas autosostenibles. }\end{array}$ & $\begin{array}{l}2 \text { Uso racional de los recursos } \\
\text { Conservación. } \\
\text { Menos presión sobre ciertos recursos. } \\
\text { Innovación: prácticas autosostenibles. }\end{array}$ \\
\hline $\begin{array}{l}3 \text { Participación local } \\
\text { Definición de roles por edad, sexo, nivel de educación y } \\
\text { etnicidad. }\end{array}$ & $\begin{array}{l}3 \text { Participación local } \\
\text { Definición de roles por edad, sexo, nivel de educación y } \\
\text { etnicidad. }\end{array}$ \\
\hline 4 Impaclo: cambios presentados a partir del ccoturismo. & 4 Impacto: cambios presentados a partir del ecoturismo. \\
\hline $\begin{array}{l}\text { El probiema de la posesión de tierras: territorio propio de la } \\
\text { comunidad Infierno. }\end{array}$ & $\begin{array}{l}\text { El problema de la posesión de tierras: territorio protegido } \\
\text { por el Estado. }\end{array}$ \\
\hline $\begin{array}{l}\text { npactos positivos y negativos antes y des- } \\
\text { mo. }\end{array}$ & $\begin{array}{l}\text { Balance de los impactos positivos y negativos antes y des- } \\
\text { pués del ecolurismo. }\end{array}$ \\
\hline
\end{tabular}


Conjunto de prácticas sostenibles

El ecoturismo se refiere al respeto por el medio ambiente, la cultura local anfitriona e incluye el desenvolvimiento de prácticas turísticas sostenibles que deben reflejarse en los siguientes aspectos:

- Conservación de la biodiversidad, del bosque y del ambiente en detrimento de las actividades tradicionalmente causantes de depredación (ej. extracción de madera, caza indiscriminada, minería).

- Mantenimiento de una progresión y continuidad económica (ganancias, beneficios locales, ingresos familiares e individuales), social (empleo), ambiental (conservación y equilibrio ecológico) y ética (transparencia en los actos e información) en el tiempo.

- Mínimas instalaciones de agua, luz y tratamiento de los desechos (desagüe).

- Revaloración de las lenguas y costumbres de las comunidades indígenas.

Carácter replicable del ecoturismo

Análisis de los efectos positivos del ecoturismo y su ponderación frente a los efectos negativos de la misma actividad y en relación con otras actividades

El ecoturismo como alternativa de desarrollo replicable para la Amazonia peruana, en función a:

- Sus efectos positivos en relación a los negativos, medidos en términos de conservación (en cantidad de hectáreas de bosques) y crecimiento económico a nivel local como de todo el país (producción interna);

- Su sostenibilidad económica, ambiental, social y ética en comparación a otras actividades de mayor impacto negativo (tala de bosques, minería, caza, etc.).

\section{CONCLUSIÓN}

La elaboración y procesamiento de datos, así como los resultados obtenidos a partir de ellos tienen como objetivo confirmar en qué medida se cumplen las siguientes proposiciones:

El ecoturismo es un vehículo para entender mejor los valores medioambientales y culturales, surgido como consecuencia de un cambio fundamental en la forma de ver la naturaleza por parte de la sociedad.

Se observa en los casos estudiados que a mayor edad la tendencia en la participación de la gente en ecoturismo es reducida, guardándose lógicamente más expectativas en el rol que las generaciones jóvenes juegan en esta actividad. Algo similar sucede con el papel de los varones frente a las mujeres, las cuales suelen estar menos informadas y participar menos del trabajo ecoturístico, ya sea por el alejamiento que les significa el mantenerse fuera de sus labores domésticas y maternales o por el temor que les significa el cambio de actividades, inseguridades que se van disipando conforme van involucrándose más en ellas. Asimismo, los niveles de educación no son determinantes para la participación en el ecoturismo, como sí lo es la flexibilidad de trabajar fuera de casa en el caso de las mujeres.
La participación de las comunidades en ecoturismo es un elemento crítico para los fines de conservación y desarrollo a largo plazo. El tipo de involucramiento de las comunidades en las actividades ecoturísticas (forma de participación local) establece la forma (sostenible o no) de interactuar con la naturaleza y el grado de conservación de los recursos generado por ello, reflejándose en que a niveles más altos de participación en toma de decisiones y control corresponden más niveles de conservación.

Desde el punto de vista de la sostenibilidad, el ecoturismo cumple con las características de una actividad económica responsable, progresiva y continua en el tiempo, en el sentido de que orienta las actitudes de los pobladores de Infierno y de Tayakome y Yomibato en relación a su forma de organización económica. Antes de desarrollarse el ecoturismo en cada grupo, su subsistencia giraba en torno a actividades que significaban el detrimento de las especies de flora y fauna de los bosques de Madre de Dios. Ahora la presión sobre determinadas especies ha disminuido en razón de que estas poblaciones han entendido el valor único que estas representan para el ecoturismo que ellos, como propietarios, están desarrollando en Posada Amazonas y Casa Matsiguenka respectivamente. 
Si bien el ecoturismo no hace a las personas más ricas, sí cubre ciertas expectativas de empleo y sueldo fijo frente a la inseguridad y baja rentabilidad generadas por la comercialización de sus productos de subsistencia, añadiendo a esto la seguridad social, entrenamiento, habilidades y la alimentación que reciben por trabajar en los albergues; mientras que para los miembros de estas comunidades que no trabajan en dichos establecimientos turísticos, estos significan un mercado cautivo de turistas donde comercializar sus artesanías.

La inserción al mercado ecoturístico de la población de Infierno y de Tayakome y Yomibato hace evidentes ciertos conflictos al interior de las comunidades en lo referente a cuestiones culturales (introducción de nuevas costumbres incentivadas por el contacto con elementos foráneos y el problema de la autenticidad ante la mirada turística), posesión de tierras (las actividades ecoturísticas están limitadas al espacio disponible según la ley de Áreas Naturales Protegidas por el Estado peruano) y división de actividades o relaciones de poder (la desconfianza de los pobladores de sus asociados: empresas o grupos de asesoramiento técnico, las decisiones sobre cuáles miembros de la comunidad han de participar en las actividades ecoturísticas). No obstante el ecoturismo permite a los mismos habitantes locales poner en discusión abierta y enfrentar sus diferencias mucho más que antes, cuestionarse por estos conflictos, discutirlos para encontrar la manera en que esta variedad de intereses y posiciones puede ser canalizada para ver cristalizar los anhelos comunitarios.

Para lograr el éxito y evitar exacerbar los conflictos, se debe buscar la gestión conjunta del ecoturismo (comunidades indígenas con empresas y agencias de desarrollo o fundaciones), haciendo acopio del saber local, revalorizando y dignificando el conocimiento que tales comunidades han heredado ancestralmente para facilitar así la transferencia de conocimientos sistematizados científicamente. Para lograr esto y disminuir la pobreza y la destrucción ambiental, las comunidades deben sentirse interesadas y beneficiadas de modo directo en los proyectos de desarrollo, como el ecoturismo, es decir pasar primero por un proceso de empoderamiento político y económico o, lo que es mejor, desarrollar su propia forma cultural e históricamente específica de apropiación material de la naturaleza.

\section{BIBLIOGRAFÍA}

\section{Amazonía, historia, archivos}

- VILLIGER, Fernando ed. 1998 Boletín de Lima, $n^{\circ}$ 125, Los Pinos, Lima.

\section{Conceptualización del ecoturismo}

- BRANDON, K. 1996 "Ecoturismo y conservación: una reseña de temas claves" in The World Bank: Environment Department Papers, $n^{\circ} 33$.

- CATER, Erlet y Gwen LOWMAN eds.1994 Ecotourism. A sustainable option?, John Wiley and Sons, West Sussex.

- EPLER WOOD, Megan Ecotourism: principles, practices \& policies for sustainability, UNEP, París.

- HALL, C. Michael 1994 "Ecotourism in Australia, New Zealand and the South Pacific: Appropriate Tourism or a New Form of Ecological Imperialism?" en Erlet Cater and Gwen Lowman eds. Ecotourism. A sustainable option?, John Wiley and Sons, West Sussex.

- LINDBERG, Kreg, HAWKINS, Donald E. eds. Ecotourism. A guide for planners and managers, vol. 1, $1^{\mathrm{a}}$ ed., North Bennington.

- LINDBERG, Kreg, EPLER WOOD, Megan, ENGELDRUM, David 1998 Ecotourism. A guide for planners and managers, vol. 2, $1^{\mathrm{a}}$ ed., North Bennington.

- PÉrez de laS heras, Mónica 1998 la guía del ecoturismo o cómo observar la naturaleza a través del turismo, Madrid.

- WEARING, Stephen y NEIL, John 1999 Ecoturismo, impacto, tendencias y posibilidades, Sintesis, Madrid.

29.11.2003 Cumbre Mundial del Ecoturismo, Quebec, 19 - 22 de Mayo de 2002, http://www.cinu,org. mx/eventos/turismo2002/doctos/dec quebec.htm 


\section{Crítica a la modernidad}

- ABDEL-MALEK, Anisuzzaman y Anouar 1983 Culture and thought, 1 a ed., The United Nations University-Macmillan Press Ltd., LondonBasingstoke.

- BECK, Ulrich 2002 La sociedad del riesgo global, siglo XXI, Madrid, 290p.

- TOURAINE, Alain 1992 Crítica de la modernidad, 1aㅡ ed. en español, Fondo de Cultura Económica de Argentina S.A., Buenos Aires.

\section{Cultura ese eja}

- ALEXIADES, Miguel N. 1999 Ethnobotany of the Ese Eja: Plants, Health, and Change in an Amazonian Society. A dissertation submitted to the Graduated Faculty in biology in partial fullfilment of the requirements for the degree of Doctor in Philosophy, UMI Company, New York.

- CHAVARRíA, María 2002 Eshawakuana, sombras y espiritus. Identidad y armonía en la tradición oral ese eja, t. I y II, Programa marco de Formación Profesional Tecnológica y Pedagógica en el Perú (FORTE-PE), Lima.

- PELUSO, Daniela M., 2003 "Variabilidad y cambio en los nombres personales en una sociedad indígena amazónica" en Amazonía peruana, t. XIV, n 28-29, 103-124.

- VIVAR A., Judith E. 1977 Los huarayo en el Madre de Dios: una introducción al estudio de cambios socio-económicos y culturales de esta etnia nativa, Pontificia Universidad Católica del Perú-Instituto Riva Agüero-Seminario de Arqueología, Lima.

- ZELENÝ, Mnislav 1976 Contribución a la etnografía huaraya (Ece'je). Contribución a la etnografia y clasificación del grupo étnico Huarayo (Ece'je), Madre de Dios, Perú, Universidad Karlova, Praga.

\section{Desarrollo social y modernidad}

- WEBER, Max 1999 La ética protestante y el espíritu del capitalismo, $17^{a}$ ed., Península, Barcelona.
- SEN, Amartya 1995 Nuevo examen de la desigualdad, Alianza, Madrid.

2000 Desarrollo y libertad, Planeta, Barcelona.

\section{Ecología humana}

- WHELAN, Robert et al. 1999 Ecología humana. Respuesta cristiana al ambientalismo radical, Libertad y Desarrollo, Santiago de Chile.

Ecoturismo en el Perú, áreas naturales protegidas peruanas, planes maestros

- Centro de datos para la conservación Conservación Internacional 1995 Reporte Tambopata. Resúmenes de investigaciones en los alrededores del Explorer's Inn, Lima.

- GUNTHER, M. 1995 "Manejo de la zona reservada Tambopata con fines de investigación y turismo" en Centro de datos para la conservación - Conservación Internacional, Reporte Tambopata. Resúmenes de investigaciones en los alrededores del Explorer's Inn, Lima.

- OHL, Julia 2004 El eco-turismo como oportunidad para un desarrollo sostenible? La economía de los matsiguenkas en el Parque Nacional del Manu, Peru, Deutsche Gesellschaft für Technische Zusammenarbeit (GTZ), Eschborn.

- PESHA, Miguel y Francisco CALA 2002 "El eco turismo como alternativa para el desarrollo sostenible de las comunidades nativas y conservación de la biodiversidad en la amazonía peruana" en Seminario: Econegocios, Biocomercio y Servicios ambientales, Inrena, Lima, 14 de octubre de 2002 .

- Profonanpe / Fondo Fiduciario Canadá 1999 Parque Nacional Rio Abiseo. Sector Oriental. Diagnóstico situacional para un plan de uso público, Profonanpe / Fondo Fiduciario Canadá, Lima.

2001 Parque Nacional del Río Abiseo. Sector Occidental, Diagnóstico situacional para un plan de uso público, Profonanpe / Fondo Fiduciario Canadá, Lima. 
- STRONZA-ROJAS, Amanda 2000 Porque es de nosotros. El ecoturismo comunitario en la Amazonía peruana. Una tesis doctoral de la Universidad de Florida, Florida (ms.).

- STRONZA-ROJAS, Amanda ed. 2003 Trueque amazónico. Intercambio de ecoturismo en Perú, Bolivia y Ecuador, Informe preliminar, Vilcabamba (ms.).

- RUIZ P., G. 1979 fundamentos y programa de manejo para uso público del Parque Nacional del Manu, UNALM, Lima.

- TOVAR S., A. 1969 Estudio del Parque Nacional del Manu con fines turistiticos y de conservación, Instituto de investigaciones forestales, Lima.

- TERBORGH, John, MACQUARRE, Kim y André BÄRTSCHI_1998 El paraiso amazónico del Perú: Manu Parque Nacional Reserva de la Biosfera, $2^{\text {a }}$ ed., Jordi Blassi.

- UNALM, PromPerú 2002 Primer informe de la situación del ecoturismo en el Perú, Lima (ms).

1986 Plan Maestro - Parque Nacional del Manu, UNALM, Lima.

\section{Ética y moral}

- SANTILlaNA, Miguel Polo Ángel 1997 Ética y crisis moral, 1a ed., Perú textos editores, Lima.

Género y roles sociales en el Perú

- DE LA CADENA, M. 1991 "Las mujeres son más indias: etnicidad y género en una comunidad del Cusco, Revista Andina 9, CBC, Cusco, 1991: 7-29.

\section{Geografía, ecología y desarrollo}

- Institute for Scientific Co-operation Applied Ceography and Development, vol. 47, Institute for Scientific Co-operation, Tübingen.

27.11.2003 La geografía y los temas ecológicos wuw.oni.escuelas.edu.ar/olimpi99/libros-digitales/html/ecologia.htm

\section{Historia ecológica}

- GONZÁLEz DE MOLINA, Manuel y Juan MARTÍNEZ ALIER eds. 1993 Historia y ecología, Ayer, Madrid.

- MARTínez ALIER, Juan 1990 "La interpretación ecologista de la historia socio-económica: algunos ejemplos andinos" en Henrique Urbano comp., Modernidad en los Andes, Centro Bartolomé de las Casas CBC, Cusco,: 255-279.

\section{Historia social del turismo}

- KHATCHIKIAN, Miguel 2000 Historia del turismo, Universidad de San Martín de Porres, Lima.

Legislación turística, hospedajes, ecolodges en el Perú

- Mincetur 27.06.2003 Reglamento de establecimientos de hospedaje del Mincetur (D.S. 0232001-ITINCI, 13.07.01), www.mincetur.gob.pe

Manejo de recursos, turismo, comunidades y desarrollo sostenible en el Perú

- CADENAS ERAZO, M. Patricia y Natalia IJU I. 2001 "Manejo de la biodiversidad: desarrollo sostenible y ecoturismo" en Henrique Urbano ed. Turismo y Patrimonio, 3, Universidad de San Martín de Porres, Lima.

- DARY, Claudia coord. 2002 Género y biodiversidad en comunidades indigenas de Centroamérica: un enfoque sobre las formas de uso y conservación de los recursos naturales, FLACSO, Guatemala.

- MORA, Carlos B. Y ZARZAR, Álvaro C. 12.08.2003 "Información sobre familias lingüísticas y etnias en la Amazonía peruana" en BRACK EGG, Antonio, Amazonia. Biodiversidad, comunidades y desarrollo, PNUD, http://amazonas.rds.org.co/Atlas/cap2/fra_cap2.htm

- PromPerú Productos turisticos sostenibles. Experiencias en el Perú, Promperú, Lima. 
Márketing turístico

- CAMPILlO GARRIGOS, Rosa la gestión y el gestor del patrimonio cultural, Murcia, KR, 1998

Medio ambiente, biodiversidad y desarrollo en el Perú

- ALEGRE, Marcos et al. 2002 El medio ambiente en el Perí. Aṽo 2001, IEC para el Desarrollo, Lima.

- BRACK EGG, Antonio 2003 Biodiversidad, pobreza y econegocios en el Perú, Lima (ms.).

- El Comencio 1999 Mi tierra, Perí, El Comercio, Lima.

\section{Metodología}

- BACHELARD, Gaston 1999 La formación del espiritu científico. Contribución a un psicoanálisis del conocimiento objetivo, 22a ed., Siglo XXI, México.

- PEARCE, Philip L., Gianna MOSCARDO y Glenn F. ROSS 1996 Tourism Community Relationships, $1^{\text {a }}$ ed., Elsevier Science Ltd., Oxford-New York-Tokio.

- EDER, Klaus 1996 The Social Construction of Nature. A Sociology of Ecological Enlightenment, SAGE, London-Thousand Oaks-Nueva Delhi.

- GÓMEZ TAGLE LÓPEZ, Erick 05.11.2005 Sociología ambiental y la reapropiación social de la natura/eza, http://mww.insumisos.com/Articulos/socio$\log \% \mathrm{C} 3 \% \mathrm{ADa} \% 20$ ambiental.pdf, $14 \mathrm{p}$.

- URBANO, Henrique 2002 "El hecho turístico: la construcción de una sintaxis metodológica para América Latina" en ALCUTH, $n^{\circ} 1$, Universidad San Martín de Porres, Lima, 63-76.

\section{Paradigma moderno}

- HABERMAS, Jürgen 1989 El discurso filosófico de la modernidad, Taurus, Madrid.

\section{Patrimonio y modernidad en América Latina}

- GARCía CANCLINI, Néstor 2001 Culturas híbridas. Estrategias para entrar y salir de la modernidad, Editorial Paidós, Buenos Aires.
Política social en el Perú

- BÉJAR, Héctor 2001 Política social, justicia social, CEDEP, Lima.

Turismo y comunidades

- ASHLEY Carolin y Delys ROE 1998 Enhancing community involvement in wildlife Tourism: Issues and Challenges.

Turismo y desarrollo

- tello rozas y Juan Carlos Paredes IZQUIERDO 2002 "Turismo, pobreza y desarrollo. Una propuesta de análisis para América Latina" en ALCUTH, $n^{\circ} 1$, Universidad San Martín de Porres, Lima, 29-51.

Tradición y modernidad en el Perú

- URBANO, Henrique 1990 Modernidad en los Andes, Centro Bartolomé de las Casas CBC, Cusco.

1992 Tradición y modernidad en los Andes, CBC, Cusco.

Turismo, patrimonio y modernidad en el Perú

- URBANO Henrique ed. 2000 Turismo y Patrimonio, 1, Universidad de San Martín de Porres, Lima.

\section{Turismo, patrimonio y modernidad}

- ARELLANO Alexandra, 2000 "Echando una mirada al tema del patrimonio", en Henrique Urbano ed., Turismo y Patrimonio, 2, Universidad de San Martín de Porres, Lima: 101-11

- URRY, John 1990 The Tourist Gaze, Sage, London.

2004 La mirada del turista, Universidad San Martín de Porres, Lima. 
Turismo, sostenibilidad turística, áreas naturales protegidas en el mundo

- Fédération des Parcs Naturcls Régionaux de France The European Charter for Sustainable Tourism in Protected Areas. Official text, Paris.

- Secretaria del Convenio sobre la diversiclad biolágic ar Diversidad biológica y turismo: desarrollo de directrices para un turismo en ecosistemas vulnerables, PNUMA, Québec.
- Secretariat d' Etat au Tourisme Tourisme, éthique et mondilisation, Ministère de l'Equipment des Transport et du Logement, París.

28.11.2003 Cumbre Mundial sobre el Desarrallo Sostenible

www.un.org/spanish/conferences/wssd/feature_story 41, htm

03. 12.2003 V Congreso Mundial de Parques, Durban, Sudáírica, det $B$ al 17 de setiembre de 2003 www.sur.iucn.org/vitrina/noticia.cfm?passcodnot $=556$. 